Delft University of Technology

\title{
Developments of energy in EU-unlocking the wave energy potential
}

\author{
Lavidas, George
}

DOI

10.1080/14786451.2018.1492578

Publication date

2019

Document Version

Accepted author manuscript

Published in

International Journal of Sustainable Energy

\section{Citation (APA)}

Lavidas, G. (2019). Developments of energy in EU-unlocking the wave energy potential. International Journal of Sustainable Energy , 38(3), 208-226. https://doi.org/10.1080/14786451.2018.1492578

\section{Important note}

To cite this publication, please use the final published version (if applicable).

Please check the document version above.

\section{Copyright}

Other than for strictly personal use, it is not permitted to download, forward or distribute the text or part of it, without the consent of the author(s) and/or copyright holder(s), unless the work is under an open content license such as Creative Commons.

\section{Takedown policy}

Please contact us and provide details if you believe this document breaches copyrights.

We will remove access to the work immediately and investigate your claim. 


\section{Title Page}

\section{Manuscript: Developments of energy in EU-Unlocking the wave energy potential}

Corresponding author's email: g.lavidas@tudelft.nl, glavidas@gmail.com (George Lavidas)

Author: George Lavidas, Ph.D.

e-mail: g.lavidas@tudelft.nl, glavidas@gmail.com

Department: Mechanical, Maritime and Materials Engineering (3mE)

Institution: Delft University of Technology (TU Delft)

Address: Mekelweg 2, 2628 CD Delft

\section{Acknowledgements}

The author would like to thank Dr. Andy MacGillivray, Dr. Brendan Cahill, Dr. Atul Agarwal and Dr. Zoe Kapetaki for their help with information concerning the study.

\section{Publication}

George Lavidas (2018) Developments of energy in EU-unlocking the wave energy potential, International Journal of Sustainable Energy, Taylor Francis, DOI: 10.1080/14786451.2018.1492578.

Link to the article: https://tandfonline.com/doi/full/10.1080/14786451.2018.1492578 


\begin{abstract}
The New Entrance Reserve (NER300) is one of the leading mechanisms used for the application and promotion of clean energy projects. In this context, this study aims to investigate the evolution of wave energy projects within the first and second call of NER300. Furthermore, the study tries to identify the reasons of successful applications through an estimation analysis of energy production, avoided emission and energy security.

Milder resources contain "hidden" opportunities for wave energy, with lower expenditure and capacity factors equivalent and even over $20 \%$. Lower extreme events indicate that associated installation costs can be considered reduced, thus the potential cost of energy may act as a positive driver for future development. The results of the study argue that there are regions with "hidden" opportunities that can accelerate proof-of-concept and enhance viability for wave energy.
\end{abstract}

\title{
KEYWORDS
}

NER300; Funding; Wave Energy; Renewable Energy

\section{Introduction}

The European Union (EU) has set ambitious targets in decarbonizing its overall energy mix, increasing energy security and adapting cleaner and renewable technologies (Parliament, 2009). Despite the recent 2008 economic turmoil, interest in energy research has not diminished, and many innovative technologies have emerged for the production of clean electricity and reduction of $\mathrm{CO} 2$ emissions.

The 2020 targets, specifically the ones concerning renewable energy production, comprise a cornerstone for the promotion and further development of innovative clean energy solutions in energy production (Parliament, 2009). In order to utilize the vast renewable resources within the European region significant infrastructure will be required and synergies of all available technologies have to be developed. One of the problems associated with renewable energy generation is the volatile and stochastic nature of resource i.e. wind irregular temporal generation that cause discrepancies and add to the maintenance cost of the electrical grid, while photovoltaic have limited daily production duration (Hedegaard \& Meibom, 2012; Schaber, Steinke, \& Hamacher, 2012; Stoutenburg, Jenkins, \& Jacobson, 2010; Verbruggen et al., 2010).

Significant steps have been introduced over the last years to analyse the system costs of modern energy systems that have socio-economic effects by the reduction of CO2, Green-House-Gas (GHG) emissions, decrease of energy imports and use of fossil fuels. Furthermore, additional solutions have been proposed for the mitigation of intermittent production by renewables allowing even $100 \%$ renewable scenarios to be examined (De Decker \& Woyte, 2013; European Commission, 2014; Friedrich \& Lavidas, 2015; Jacobson \& Delucchi, 2011; Jacobson et al., 2017).

Major economic benefits are reported in literature that support the increase for renewable energy penetration. Krozer (2013) estimated that 9 billion $€$ can be gained by the European Union (EU) Member States (MS), from reducing energy dependence by external sources, not including the potential job growth rates and additional economic development from the evolution of new industries. Although the technologies exist the necessity for proper financing and development are imperative, as often such solutions are based on new innovative approaches in renewable energy production (Abdmouleh, Alammari, \& Gastli, 2015; Hervás Soriano \& Mulatero, 2011).

The New Entrants Reserve (NER300) was a call funded by the European Parliament (EU), European Investment Bank (EIB) and Member States (MS), in order to 
promote, finance installations, and test of innovative solution for the decarbonisation of energy in Europe (European Commission, 2017). This resulted in two phases that were open for clean energy projects, including Carbon Capture and Storage (CCS), Biomass, Biofuels, solar, photovoltaic, wind (onshore and offshore), geothermal, hydropower, smart grids, wave and tidal. The financial funds of the calls were derived by the selling carbon prices of 300 million allocated Emissions Trading System (ETS) credits. The target was that the NER program could funnel 4.5 billion $€$ into innovative research. Unfortunately, this was not the case with the first call amounting just over 1.1 billion $€$ from $\mathrm{CO}_{2}$ credits and approximately 1 billion from the second call. This prompted funds to be also met by further resources of approximately 3 billion $€$ from external and private entities (European Commission, 2017). Overall the EU funds provided where about 2.2 billion $€$ for the first and second call, leading to the funding of thirty-eight (38) RE projects and one (1) CCS, which have shared the financial incentives.

\subsection{Gap of information}

The purpose of this overview study is two-fold, first to assess the energy, increased energy security and avoided emissions by the awarded wave energy projects. Descriptions of projects in the public domain offers insight on technologies that were awarded funds, they do not provide public data concerning estimated production, energy security and avoided emissions. The energy modelling assumptions are based on previous studies and the authors energy modelling experience of wave resource that allows the quantification of expected energy production. Therefore, providing insights to expected production levels, which contributed (to a part) to project selection.

Second target is to discuss the benefits that wave energy installations can have with deployments in milder conditions. Focus is given in the Mediterranean Sea, that is often is overlooked. To strengthen the perception of wave energy possibilities and hidden opportunities, investigation for application in milder waters is proposed. Potential benefits include capital expenditure reduction, while significant contributions can be gained in regards to energy production, emissions reduction, and avoided imports. In addition, wave energy applications at milder resources offer significant opportunities for the proof-of-concept of such technologies accelerating their maturity and enhancing their Technology Readiness Level (TRL).

\section{Wave Energy Perspectives}

Wave energy has been developing over the last few decades, with recent years having spearheaded and further proved the applicability and performance of wave energy converters (WECs). Evolution of WECs application has been slow, particularly in regards to further deployments subsequent to initial testing. The engineering aspects of ocean energy extraction have been built on sound basis over years of research. Many test facilities have initiated operations, proving the real time potential benefits by wave energy applications. Several studies have been conducted around Europe for the constrains and benefits that are associated with wave energy (Magagna, Monfardini, \& Uihlein, 2016).

Wave energy presents an untapped energy resource, which has a much higher energy density, than wind or solar. In addition, physical characteristics of waves make it less volatile than wind, and much more predictable. With advancements made during past 
years in numerical methods and High Performance Computing (HPC) clusters, we are in position to deliver resource assessments, hindcasts and forecasts for waves in great accuracy allowing for better understanding of their capabilities (Reikard, Robertson, \& Bidlot, 2015; Sasaki, 2017).

As seen in Fig. 1 energy density along the coasts of Europe is significant. Wave energy depends on the so-called significant wave height and energy spectral period. Both being elaborate notations within the oceanographic and wave energy community (Ingram, Smith, Bittencourt-Ferreira, \& Smith, 2011) which are not explained in this study, as this will deviate from scope of the article. However, an important quantity one has to keep in mind is that wave energy resources are expressed in $\mathrm{kW} / \mathrm{m}$, meaning that for every meter of wave crest the energy contained within the waves is counted in $\mathrm{kW}$. Current developments have increased accuracy of the numerical methods used and have allowed us to better represent the resource of a region. Recent works carried out by the authors have improved the wave site characterization and resource assessments of the Scottish and Mediterranean region (Lavidas, 2016; Lavidas \& Venugopal, 2017a, 2017b). Previous literature on available resource both in the North Sea, West European coastlines and Mediterranean can be found in Lavidas and Venugopal (2018).

Wave quantities are represented usually by the description of available mean resource, with seasonal and annual variations. Having quantified wave energy resource for a region, wave energy converters can be used to extract energy and convert it into useful renewable electricity. Currently many different WECs are in development, with significant differences located in their power-take-off systems (PTO). The operating principles and the PTO allow for energy production, although WECs can also have additional "innovative" characteristics that are associated with their embedment in coastal areas and/or their potential multiuse functions. WEC classification is often done by the characteristics and operating principles of devices (Falcão, 2010). Finally, one more approach to WEC classification can be considered based on the respective size, however these might obtain sub-divisions with similarities to the classification based on operation principles (Babarit et al., 2012; Day et al., 2015). Some of the basic energy extraction principles are provided in Fig. 2.

While differences in structural construction, deployment techniques, and rated capacities exist there are some basic principles for which wave energy converters are classified. In general terms three classifications can be attributed according to depth, as deep, nearshore (coastal) and shallow water (Magagna \& Uihlein, 2015). Though this is convenient, it is not entirely true for operating principles which can be divided in several systems such as oscillating water columns (fixed or floating), heave buoy systems (encompassing quite a significant number of smaller sub-divisions such as single body, two-body heaves, pitching devices etc.), attenuators, bottom hinged, multi-body system and overtopping technologies, for a more in-depth look on different converters and their operating principals, the reader is diverted to other more relevant studies (Babarit, 2015; Babarit et al., 2012; E. Rusu \& Onea, 2018). In terms of the "innovative" nature of WECs to act as coastal defences structures several examples have shown the real-world viability of such systems (Arena, Romolo, Malara, Fiamma, \& Laface, 2017; Takahashi, Nakada, Ohneda, \& Shikamori, 1992; Torre-Enciso, Ortubia, de Aguileta, \& Marques, 2009). Energy performance and capital requirements are dependent on regional resource and have to be accounted for prior to deployment (Contestabile, Di Lauro, Buccino, \& Vicinanza, 2017; Ibarra-Berastegi et al., 2018; Pecher, Kofoed, Le Crom, Neumann, \& Azevedo, 2011). Some of the mentioned categories are presented in Fig. 3.

With such a wide variety of technological solutions, there is added difficulty in 
assessing potential projects for further examination or deployments under investment of funding schemes. The performance of each device is heavily dependent on the site selection, local resource, variability of the climate and given range of operation for the device. So far, most energetic resources identified are into the North and West open Atlantic coasts of Europe, with the majority of research and development is carried out for devices in highly energetic environments. Due to the innovative nature of the technologies and the level of small commercial exposure, WEC application are heavily dependent on the funding schemes set by various governmental and EU sources. Though some countries have already adopted initial consideration of selling prices and/or certificates schemas for wave energy electricity in hope of further development (Fraunhofer \& ECORYS, 2017; Magagna et al., 2016; Ocean Energy Forum, 2016).

These financial schemes aim not only to develop the research and development in the industry but also to help disseminate the potential the technology has, quantifying potential yields in energy and emission reductions. Within the NER300 framework, several RE technologies have been considered and awarded funding support from both the first and second call. Ocean energy was represented by ocean thermal, wave and tidal. Because the rejected and/or withdrawn proposals are not available for public information, only the accepted wave energy applications are examined.

In summation, all ocean energy projects acquired 141,985,151 million $€$. While the amount of money seems to be significant, the overall allocated funds for ocean technologies represents $\approx 6.5 \%$ of NER300 funds. The majority of the funding was diverted to more mature technologies. Biomass acquired the most funding with $42 \%$ followed by wind $15 \%$, one project of CCS $14 \%$ and solar (14\%), see also Fig. 5 . It has to be noted that NER300 has a specific restrictions on the maximum allocated percentages per technology, specifically no technology can be awarded more than $15 \%$ of the overall funds.In Fig. 5 Biomass amounts $42 \%$, that is because we have not separated the technology sub-categories e.g. oxy-fuel, biomass, biofuels, pyrolysis etc., but rather considered the overall technology as a whole at the end stages (Commission, 2017; European Commission, 2009).

This example of technology and limitation of funds can be seen with the CCS awarded submission; the WhiteRose CCS plant acquired all 14\% since other technologies failed the submission stage, with other CCS projects using different engineering approaches (Kapetaki \& Scowcroft, 2017). Unfortunately, the data for these processes are confidential and cannot be presented in the study.

During the first call ocean energies funds went to two tidal projects, while the second call saw the approval of wave projects, see Table 1. Tidal technologies are considered more "mature" and ready for deployment than WECs. However, there are significant, barriers concerning the applicability of tidal devices around EU, with most sites located in the UK. While, no information are available for the projects that did not receive funding, initial scope showed that all ocean projects granted funds (wave and tidal) are located in traditionally highly energetic locations.

This is the obvious solution in terms of potential energy returns, but this comes with associated higher costs. The wave environment in the Atlantic coastal regions is very harsh and variable, raising issues in the conditions that may compromise the survivability of the device (OES, 2015). This is reflected in the estimations and projections of capital expenditure (CAPEX), operation (OPEX) and strengthening works for the deployment of such facilities, which drive the initial capital higher (Astariz, Vazquez, \& Iglesias, 2015). 


\section{Proving Reliability within NER}

One of the major targets for wave energy and the NER300 is the acquiring of funding to deploy technologies and prove that wave energy is applicable and reliable when it comes to energy production. Proving the reliability of wave energy technologies is vital for the wave community, since only through demonstration plants and comparable results can it reduce its current high capital (CAPEX) cost, and achieve reduction in cost of unit per MW. In energy terms the ability of the wave devices has been proven in numerous occasion with test facilities and small trials at real sea condition, although "larger" demonstration projects are still the key in potential cost reduction for the technology (Magagna et al., 2016).

The NER300 framework has specific conditions concerning the allocation of funds. In terms of funding, no project can amount more than $50 \%$ of its total estimated expenditure, meaning that the rest $50 \%$ of the cost has to be by the Member State or private sources. Moreover, the award process required specific technical information to be estimated prior to the selection, while not all the actual information are public domain, NER300 required especially from renewable energy projects (RE) the outline plans of device selection, expected electricity production (European Commission, 2017). Following the energy estimations the cost levels of CAPEX, OPEX, installation costs, and cost per MW (or cost per unit) had to be presented. Subsequently, potential drawbacks for the construction of the project have to be identified, alongside with the development of Health and Safety practises. Finally, the environmental impacts had to be estimated and present the level of avoided emissions. The estimated production levels was one of the key pillars for the assessment of installations, our study focuses and compares the two wave energy awarded projects and their potential technical deliverables.

The WestWave project is a 5 MW project that was to be deployed at the Killard Point in County Clare, Ireland. Each nominated WEC is to have a 1 MW rated capacity while the overall wave farm reach $5 \mathrm{MW}$ in capacity. The project was initially awarded 19.8 million $€$ from the 1 st call round (withdrawn) while on the second call this was increased to approximately 23 million $€$. The project withdrew from the first round due to a lack of available technologies that would hinder it by reaching the requirements in intended timeframe. While, two technologies were considered for deployment current developments in the wave energy sector have pushed back the selection of final device to be used and the date of completion pushed to 2018 instead of 2015, with device selection status pending. These drawbacks have stalled, the deployment actions are taken involving a detail resource characterization of the area, onshore works, public engagement, and environmental assessments. Apart from the awarded NER300 funds the work is also partially funded by the Sustainable Energy Authority of Ireland (Brendan, 2015).

The second successful project is the SWELL project in Portugal, located at the West Atlantic front of the country. In contrast to WestWave, the SWELL wave farm will have a nominal installed capacity of 5.6 MW and will consist of sixteen (16) wave converters of rated power $350 \mathrm{~kW}$. The WEC selected is an oscillating Wave Surge which is anchored to the seabed (Commission, 2017). While the energy estimations and submitted proposal are unknown (not in the public domain), some assumptions can be made for the expected production levels. Furthermore, project costs can be directly associated through the known percentages of allocated funds limits, and thus the estimated additional funding by private entities or the contribution by the Member State as discussed in the previous section. 
The energy production of a WEC is closely related to location resource, with costs higher for energetic areas since the return period of extreme events are expected higher and requires more strengthening infrastructure works. Previous studies have examined the capacity factors that expresses the capabilities of WECs production (Astariz \& Iglesias, 2015; O'Connor, Lewis, \& Dalton, 2013; L. Rusu \& Onea, 2015). Energy performance is highly dependent on matching the metocean conditions to the WEC operational principles (Ibarra-Berastegi et al., 2018; Lavidas \& Venugopal, 2017a; Lavidas, Venugopal, \& Friedrich, 2017; E. Rusu \& Onea, 2016; L. Rusu \& Onea, 2015, 2016). Resource dominant characteristics have a profound effect on the expected energy generated by WECs. matching dominant condition to WECs, requires coupling of longterm resource assessment with power matrices. L. Rusu and Onea (2015) examined several locations in the United Kingdom, Portugal, Spain and Norway and coupled metocean data with WECs. E. Rusu and Onea (2016) performed a similar assessment in energetic locations in the Atlantic focused at the island of Iceland, Azores, Madeira and Canary. The authors used a classification of WEC according to applicable depths. Their findings showed that selecting WEC operation based on metocean conditions can assist in the dissemination process, and showed that matching operating principles with resource provides useful metric like the capacity factor.

Lavidas (2016) utilised a high resolution spatial mesh examined the wave climate, power resource, WECs energy performance, and extreme conditions around multiple locations of the Scotland for 11 years, the dataset was used to also examine the coupling and performance of six WEC at the Scottish coasts (Lavidas et al., 2017). Based on metocean couplings and depth deployments the energy performance of the WEC ranged from $15 \%-30 \%$ for deep locations and from $\approx 6 \%-22 \%$ for nearshore. The study discussed the importance of correct coupling of WECs to the locations, which was evident by the lower utilisation rates. Based on available literature and previous experience the capacity factors of locations at higher latitude and exposed to the Atlantic are within a range of $20-40 \%$, a $5 \%$ increment is used ensuring that this range provides realistic expectation of production in terms of low and high production levels, see Table 2.

Production is estimated with high, low and medium scenarios, it has to be noted that the funds awarded by the NER300 are difficult to identify i.e. what percentage of the final project cost are represented by NER300 public funding and which is the private funding, since these information are confidential (Commission, 2017; European Commission, 2009).

The differences in projects cost can be somewhat explained through examining the available resource, probabilities of return periods, which are expected to lead in increases of capital costs that will ensure the reliability, and survivability of the devices. Such interactions include the extreme value analysis of the regions the necessity for foundations, moorings, support structures, WECs technology, electrical connection lengths, vessel require, although such studies are not often taken into account (Astariz \& Iglesias, 2015). Current estimations suggest that the support structures and logistics, account for approximately $25 \%$ while the fixed annual maintenance cost are variable cost account for around 10-30\% of the CAPEX (Badcock-Broe, Flynn, George, Gruet, \& Medic, 2014; Magagna \& Uihlein, 2015). The largest costs are associated with moorings, chains, lines, anchors, connectors, clump weights. The size and necessity of which are indicated usually by the highest extremes that are to be encountered (Badcock-Broe et al., 2014; Ingram et al., 2011; Ocean, 2013).

From this standpoint exposure of Ireland to harsher events is much higher, with return period and waves reaching and exceeding over 15 meters, while the Portuguese 
coast is exposed to somewhat lower return values (Sterl \& Caires, 2005; Vinoth \& Young, 2011). In both cases, the necessary reliability and survivability increase the CAPEX in the infrastructure sections (Badcock-Broe et al., 2014).

Assessment of benefits from the projects is based on energy production, the cost of MWh produced in comparison with the level of NER300 funding (public return cost), avoided $\mathrm{CO}_{2}$ emissions, and avoided imports of tonnes of oil equivalent (toe) by renewable energy produced. The additional avoided emissions and can act as an indicator for environmental benefits and increased energy security that can be achieved by WEC farms, reaffirming the fact that wave energy is able to deliver environmental benefits and decrease energy imports if applied.

Considerations of emissions reduction taken into account include two types of fossil fuel, oil and natural gas (NG), with respective emissions corresponding to information provided by the Environmental Protection Agency (EPA, n.d.). The tonnes of oil equivalent (toe) is a widely accepted quantity used to assess the quantity of energy (or content) of energy within a tonne of oil, estimations within the study are based on the equivalence of 1 toe $=11.63 \mathrm{MWh}$ as suggested by the International Energy Agency (IEA, n.d.).

All incremental scenarios show that wave energy farms can yield significant annual production, see Fig. 6. To estimate the energy production of WEC, the bivariate distribution of metocean data is combined with the power matrix and representative Capacity Factor (CF) values can be obtained (Lavidas et al., 2017; E. Rusu \& Onea, 2016). Such estimated values always depend on the available level of information. The public return cost is reduced significantly after the medium level scenario $(\mathrm{CF}=30 \%)$. Of course, the corresponding capacity factor will depends heavily on the selection of device, although most current technologies are developed for such climates thus the estimated utilization rates should be within the range. While, wave energy is at preliminary stages of proving large scale reliability, energy production estimates reveal that the amounts of energy are not to be overlooked. Even with the low scenario the wave farm yields $\approx 9 \mathrm{GWh}$ for Ireland and $10 \mathrm{GWh}$ for Portugal.

Furthermore, environmental benefits also are enhanced (Azzellino, Lanfredi, Contestabile, Ferrante, \& Vicinanza, 2011; Boehlert \& Gill, 2010; Leeney, Greaves, Conley, \& O'Hagan, 2014; Margheritini, Hansen, \& Frigaard, 2012); see Fig. 7, by the introduction of farms the emissions can significantly reduce by several MTn of $\mathrm{CO}_{2}$. Of course, developers can benefit within the European Emissions Trading Scheme (ETS) to add an additional revenue stream by using avoided emissions certificates, but since the price of ETS has not been stabilised no such considerations are taken in the study. This was obvious in the initial estimates of the NER300 where final funds collected were less than estimated due to dropping prices in the emissions allocated.

Another factor seldom taken into account is the nature of wave and their dependence on wind. Waves act a "storage" medium that retains the energy infused by wind. Thus, if wave energy is considered within a wider scope it can reduce variability of wind and other renewable technologies. The correlation of wind and wave has been investigated and there is a significant time difference between the resources allowing predictions on production being reliable and add benefits to the transmission operators of the local electrical grid or with local storage medium, reducing intermittent production (Cradden, Mouslim, Duperray, \& Ingram, 2012; Friedrich \& Lavidas, 2015; Lavidas \& Agarwal, 2017). 


\section{Unlocking Wave Energy Opportunities}

Wave resource levels have a significant role in the site selection, development, and proposals of wave energy farms. The two projects awarded NER300 funding are both located in the most energetic parts of Europe the East Atlantic front. While this benefits energy potential, it also increases the capital expenditure required to ensure operation reliability and survival of WECs, as discussed in the previous section.

Reliability and proof of concept at this point of the wave energy industry are amongst the most important considerations. With a higher number of proven installations at real conditions, potential problems not located during development stages (i.e. tank testing, research sites, small-scale tests) are discovered. This will allow the refinement and improvement of the current technologies, as well as the important individualization of WECs to be adaptable for various sea states. With funds such as the NER scheme being able to provide start-up opportunities for validation and exploration, it is important to find appropriate locations that will test the reliability, without compromising the devices.

Due to the nature of open seas (oceans), harsher conditions are met often and at higher magnitude, increasing the focus on survivability aspect. Moreover, often times extreme events surpass estimations and can deliver catastrophic results to the wave farms, thus affecting the installations, survivability, reliability, and cost required. One over-looked region that can facilitate wave installations is the Mediterranean Sea.

The wave environment is significantly different from one of the West coastline of Europe. The wave conditions include smaller fetches, in comparison to the Atlantic. The bathymetry has sudden changes in depths, which affect the propagated waves (bottom friction), and the surrounding coastlines reduce the resource by enhancing non-linear effects affecting the resource levels. This leads to lower levels of resource in the region. While this may be seen as a drawback, it can prove a benefit to wave energy farms because the extremes events are also lowered. The wave resource in the Mediterranean Sea is significantly lower than the Atlantic, as expected. Milder resources, tend to have less magnitude variations over the long term, within the order of $0.25 \mathrm{~m}$ (Makris et al., 2016). This can lead to more "stable" seasonal and/or annual resources, with smaller energy variations when compared with higher resources regions that can have a difference of 1-1.5 m (Lavidas, 2016). Such low energy variations can be significantly advantageous for energy performance.

When it comes to return periods (extreme values) the indicative maps for the UK, Ireland and Greece (Agarwal, 2015; Zacharioudaki, Korres, \& Perivoliotis, 2015), exhibit the nature and difference in magnitude encountered (see Fig. 8). It is obvious that the metocean conditions in a basin such as the Mediterranean deliver less extreme events, this affects the considerations in engineering applications and deployment of WECs decreasing the costs of installation.

WECs and wave energy as a potential resource has also been investigated by various countries in the region, which dealt with the application, simulation and expected production levels by single or multiple WECs around Mediterranean countries (Bozzi, Milano, \& Passoni, 2011; Vicinanza, Cappietti, \& Contestabile, 2007; Vicinanza, Contestabile, \& Ferrante, 2013). In milder environments low operational class devices are preferable, Lavidas and Venugopal (2017a) estimated that such out of the shelve WECs can obtain values from 15-20\%. In addition, Luppa, Cavallaro, Foti, and Vicinanza (2015) went a step further and re-scaled the WECs to match the conditions attaining capacity factors $\approx 30 \%$ with the option of further improvements close to $35 \%$. Preliminary analysis, which are out of scope, indicate that WECs which are able 
to operate at lower occurrence sea-states present a favourable exploitation rate, a fact that was can be also examined by other studies as well (L. Rusu \& Onea, 2015), with associated capacity factors ranging from $10-30 \%$ in similar low energetic regions in the Mediterranean. This of course is highly dependent on the selection and adaptability of a WEC to the local resource. Other studies have also explored the benefits of adapted operation WECs for the region (Bozzi, Archetti, \& Passoni, 2014; Bozzi, Miquel, Antonini, Passoni, \& Archetti, 2013) and recent developments explored similar trends (Vicinanza et al., 2015).

A sensitivity analysis concerning a WEC application in the Mediterranean is tested with the following assumptions as seen in Table 3. Other studies examining the costs, payback periods, cost of electricity, reduction opportunities for WECs can be found in (Allan, Gilmartin, McGregor, \& Swales, 2011; Ocean, 2013; O'Connor et al., 2013). Since wave energy is considered an emerging technology associated capital requirements as expected are high.

While that is true, associated wave energy costs are also site and area specific, the cost of a WEC can be broken down to several parts, for early wave array deployments the cost considered are the structure, PTO, foundation and mooring, installation, grid connection and maintenance. The most capital intensives of these components are PTO cost, installation-foundation-mooring 10-20\% of the CAPEX (dependent of WEC selected) while the maintenance and operation is highly dependent not only on the WEC but also at the location, distance from shore and local weather conditions, thus usually a fixed annual maintenance cost can be ranging from 10-30\% of the CAPEX (Astariz \& Iglesias, 2015; Astariz, Vazquez, \& Iglesias, 2015; Magagna et al., 2016; Magagna \& Uihlein, 2015; Magagna, Uihlein, Silva, \& Raventos, 2015; Ocean, 2013). Licensing costs, variable and de-commissioning costs have not been taken into account similar to (Allan et al., 2011; Astariz, Perez-Collazo, Abanades, \& Iglesias, 2015).

The CAPEX range taken within the study, is adapted by values mentioned in published literature and considering the lower values of extreme values and necessity for strengthening the wave energy converters (OES, 2015), while for the Mediterranean (Bozzi et al., 2011) considered a cost for a device in the range of $2000 € / \mathrm{kW}$ as well. The sensitivity analysis within this study considers an indicative installed capacity of $5 \mathrm{MW}$, the capacity factor due to the fact that is region specific is altered by $2.5 \%$ in order to provide a characterisation for the majority of WECs that can be applied to the Mediterranean Sea (Lavidas \& Agarwal, 2017; Lavidas \& Venugopal, 2017a), the energy of each converted is estimated by Equation 1. The costs represent the Capital Expenditure of a WEC expressed in $€ / \mathrm{MW}$ and are also incremented by $250 \mathrm{k} €$ in order to represent "viable" solutions based on amortisation periods in the Mediterranean area (Lavidas \& Venugopal, 2017a).

$$
E_{o}=P_{o} \cdot \Delta T \cdot C F
$$

with nominal rated capacity $P_{o}$, the hours in a year $(\Delta T)$ and $E_{o}$ energy produced. Furthermore, to quantify the potential benefits of WECs, the avoided imports of energy that increase energy security have been included, i.e. avoided energy oil imports estimated in $€ /$ barrel of oil equivalent (bbl). A bbl is the quantity used for the storage, moving, and capacity of a barrel of oil. It ranges from capacity of $100 \mathrm{Kg} / \mathrm{bbl}$ to 200 $\mathrm{Kg} / \mathrm{bbl}$, in this study we have considered a bbl to be equivalent to $150 \mathrm{Kg}$. Moreover, based on current prices of oil (Bloomberg, n.d.) a barrel of oil is sold approximately 
at $55 €$. On these bases the following Fig. 9 estimates energy production and avoided $\mathrm{CO}_{2}$ emissions can be seen for the a WEC under variable sensitivity control.

The resource of the Mediterranean region is $\approx 10-15 \mathrm{~kW} / \mathrm{m}$ at "hot-spot" wave energy regions in the winter and early spring months (Lavidas, Venugopal, \& Agarwal, 2016 ), in contrast to similar months at higher latitude that can be $\approx 30-60 \mathrm{~kW} / \mathrm{m}$ (Lavidas \& Venugopal, 2017c) (at viable WEC depths). The milder resources found at the region, indicated that the metocean parameters and more specifically significant wave heights are reduced. This means that WECs which favour operation at higher energetic environments, i.e. their range of operation produces more at higher wave heights, shall not be as productive and will obtain lower CFs. Therefore, as a crude estimate such converters can be described by lower CFs $(\leq 15 \%)$, see Fig. 9, while WECs that favours operation will tend to have higher CFs $(\geq 17.5 \%)$. This will also affect the estimated $\mathrm{CO}_{2}$ reduction levels.

Since the sensitivity analysis is based on future proposed scenarios, the cost of MWh from the wave farms depends solely on the estimated cost that will be required to ensure viable operation. As mentioned, current estimates are dependent on the WEC chosen, while the cost of installation varies and dependent on local conditions. The Cost of Energy (COE) is amongst one of the indices used to estimate the economic performance of a WEC. This is expected to be high for early deployment the learning rates and expected COE reductions as installations increase are promising (Astariz, Perez-Collazo, et al., 2015; Badcock-Broe et al., 2014; Dalton et al., 2015; Ocean, 2013).

The proper selection of WEC corresponds to a scenario approach based on the local resource, with the cost of energy (COE) dependent on the production at the site and the cost of installation, a COE for this study is used, since the uncertainties associated with Levelised Cost of Energy (LCOE) in so preliminary level technologies are great. Such uncertainties include the varied levels of infrastructure costs, non-uniformity over the discount rates that are to be used, variability and lack of knowledge concerning the operational costs.

The Cost of Energy is estimated as the cost (see Table 3) over the annual energy production (as estimated by Equation 1). In this instance, the cost of energy is as low as $11 \mathrm{c} € / \mathrm{kWh}$ (low cost/high CF scenario), see Figure 10. On the other hand, for a WEC not compatible with the resource the low cost/low CF scenario gives a value of approximately $34 \mathrm{c} € / \mathrm{kWh}$. If the WEC is not suitably selected to accommodate the sea-states, in terms of production or if a low area of resource is chosen, then the cost are significantly higher with values reaching over $68 \mathrm{c} € / \mathrm{kWh}$ (high cost/low CF scenario) and $23 \mathrm{c} € / \mathrm{kWh}$ (high cost/high CF scenario). While this does not constitute a thorough life-cycle analysis of wave farms, similar range values have been found concerning cost and performance (Badcock-Broe et al., 2014; Ocean, 2013). No potential subsidy schemes are explored in the calculations which would reduce the CAPEX, although they are available for renewable energies in some Mediterranean countries (France, 2007; GSE, 2015; Spain, n.d.).

Energy that is produced from wave farms, as in the case of other renewables, has not only environmental benefits but additional financial as well. Potential certificates can be traded through the ETS system or similar system (i.e. Renewable Obligation Certificates (ROC)) and add revenues to both developers and countries. The avoided energy imports can also benefit the overall financial picture, with some of the earned funds allocated to local infrastructure projects in order to strengthen the transmission grids for higher renewable acceptance. The small wave farm investigated here can reduce the amounts of equivalent barrels of oil aiding to the energy security and 
revenues, see Fig. 11.

Even with current prices of oil products remaining at all-time lows, the suggested wave farm can contribute in reducing financial imports as high as 400 thousand Euros ( $\mathrm{k} €$ in high scenario), while with an unfavourable scenario the monetary dependency can reach slightly over $100 \mathrm{k} €$. By the adoption of wave energy in the energy mix, the temporal variability of other renewables can be complemented, this indicates that additional financial benefits by investment deferral can multiply. Increasing diversification of the energy mix and contributing to a sustainable and secure energy option.

By application in milder environments the cost of infrastructure and strengthen works required are reduced, since they often depend on the expected extremes of location that affect survivability. Moreover, the proper selection of WEC ensures that its range of operation will cover majority of the sea-states encountered. This although, is proposed to be done by long-term combination of numerical modelling with the characteristics of the device. Investigating application of novel technologies, such as wave energy, in milder environments may offer lower installation costs in contrast to the open oceanic locations, higher reliability, and can be the driver for proof-of-concept of wave energy.

\section{Discussion}

In this study, the awarded wave energy projects from the NER300 were presented and examined. While limited information exist concerning their expected benefits, energy modelling allowed the estimation of energy benefits, in close agreement with previous literature. The selection of wave energy in the NER300 was of major importance for the development of the wave energy industry. Through them significant outcomes are expected that would strengthen the reliability by proven installations. The two projects selected are located at the open Atlantic coast of two European countries, while such regions have higher resource levels, this is also expected to increase their capital requirements for infrastructure to ensure survivability.

Ocean energies within the NER300 had success, although in comparison to the overall NER300 budget, ocean energies accounted only for 6\%. One can argue that limitations within wave energy is the high capital expenditure, and regional focus. Majority of projects was focused on the Atlantic, raising the capital expenditure and creating a very competitive environment within the industry to access funds. The main focus of NER300 is the proof-of-concept for innovative technologies, the wave energy community should take advantage and expand its regional interests to lower and milder environments. This will allow the consideration of lower capital, due to less harsh event, with installation of WECs that match dominant metocean conditions.

The importance of funding opportunities, such as the NER300 is of major concern for research, application, and displaying the potential of emerging technologies. With future calls similar to the NER300 in their way, regions with milder resources though pose "hidden" values when it comes to wave energy. Considerations on the applicability of WEC in milder European regions can prove beneficial for acceleration of the sector. Similar to NER300, there are discussion on releasing the NER400 that intents to provide funding for innovative projects again in the future. The scheme structure will again be intended for European regions and at the time of this manuscript is still under discussion. However, it is highly likely that the focus will again be on novel technologies that require "acceleration" funds, ensuring however they can deliver cost effective solution with multiple benefits (NER400, n.d.). 


\section{Conclusions}

This overview of successful NER300 wave energy projects estimates, and presents the awarded projects. Due to lack of information available, the study uses existing literature on WEC application and tries to provide quantified energy estimates, which may have helped to successful applications.

One of the lessons that the NER300 provides is the mindset of energy and cost effective project application. Considering that wave energy urgently can benefit from proof-of-concept installations, and reliable energy performance to reduce capital expenditure. A different approach is proposed for future application of similar farms based on the indication that milder conditions locations will require less capital and operational costs. Since the selection process of similar to NER300 calls is dependent on technology type, innovation status, capital required and capital met, the validation and proposal of a WEC in a milder climate sea would benefit the wave energy industry.

The estimations provide with preliminary findings on the energy estimation, $\mathrm{CO}_{2}$ emission avoidance, and energy imports reduction. Through a thorough sensitivity analysis, the energy production of a suggested wave farm was estimated, alongside with the estimated costs and benefits. It is shown, that even for conditions met in the Mediterranean, energy yields can still be significant delivering thousands of MWh even with current WECs.

The sensitivity analysis of wave energy in the region, also provides with the expected energy benefits, financial, environmental benefits, and capital required. A small increment analysis revealed the necessity for proper selection, which would lower the initial cost of the installation. From an energy standpoint, all the scenarios tested showed that even with a small wave farm application, the yields could amount significant results even at lower resources, given the current pre-commercial status of the technologies. In addition, availability of the resource in comparison to range of WEC operation expected to be higher, since high wave occurrences are often not met in the area. This also leads to environmental benefits comparable from other renewable technologies.

Diversification of the energy mix is expected to contribute to the increase of energy security (energy imports avoidance), but at the same time stabilizing the intermittent nature of renewable energy production, will require more innovative approaches. The nature of wave energy can secure that the increasing energy demands can be met in a sustainable way. Future investigation for such application can accelerate installation rates, reduce costs whilst increase awareness of the possibilities and potential by either WEC alone or through synergies. Wave energy has the potential to prove beneficial and contribute to various regions, while its application in suitable environments, not only highly energetic, is bound to increase the confidence for overall development of the sector.

\section{Acknowledgements}

The author would like to thank the reviewers for their constructive comments that improved the quality of the manuscript.

\section{Disclosure}

The author discloses no conflict of interest. 


\section{References}

Abdmouleh, Z., Alammari, R., \& Gastli, A. (2015). Review of policies encouraging renewable energy integration \& best practices. Renewable and Sustainable Energy Reviews, 45, 249-262. Retrieved from http://linkinghub.elsevier.com/retrieve/pii/S1364032115000453 doi:

Agarwal, A. (2015). A long-term analysis of the wave climate in the North East Atlantic and North Sea (Ph.D Thesis). University of Edinburgh, Edinburgh.

Allan, G., Gilmartin, M., McGregor, P., \& Swales, K. (2011). Levelised costs of Wave and Tidal energy in the UK: Cost competitiveness and the importance of "banded" renewables obligation certificates. Energy Policy, 39(1), 23-39. Retrieved from http://dx.doi.org/10.1016/j.enpol.2010.08.029 doi:

Arena, F., Romolo, A., Malara, G., Fiamma, V., \& Laface, V. (2017). The first full operative $\mathrm{u}$-owc plants in the port of civitavecchia. In Proceedings of the international conference on offshore mechanics and arctic engineering-omae (Vol. 10). doi:

Astariz, S., \& Iglesias, G. (2015). The economics of wave energy: A review. Renewable and Sustainable Energy Reviews, 45, 397-408. Retrieved from http://linkinghub.elsevier.com/retrieve/pii/S1364032115000714 doi:

Astariz, S., Perez-Collazo, C., Abanades, J., \& Iglesias, G. (2015). Co-located wave-wind farms: Economic assessment as a function of layout. Renewable Energy, 83, 837-849. Retrieved from http://linkinghub.elsevier.com/retrieve/pii/S0960148115004073 doi:

Astariz, S., Vazquez, A., \& Iglesias, G. (2015). Evaluation and comparison of the levelized cost of tidal, wave, and offshore wind energy. Journal of Renewable and Sustainable Energy, 7(5), 053112. Retrieved from http://scitation.aip.org/content/aip/journal/jrse/7/5/10.1063/1.4932154 doi:

Azzellino, A., Lanfredi, C., Contestabile, P., Ferrante, V., \& Vicinanza, D. (2011). Strategic environmental assessment to evaluate wec projects in the perspective of the environmental cost-benefit analysis. In Proceedings of the 21st international offshore and polar engineering conference international society of offshore and polar engineers. doi:

Babarit, A. (2015). A database of capture width ratio of wave energy converters. Renewable Energy, 80, 610-628. Retrieved from http://linkinghub.elsevier.com/retrieve/pii/S0960148115001652 doi:

Babarit, A., Hals, J., Muliawan, M., Kurniawan, A., Moan, T., \& Krokstad, J. (2012, may). Numerical benchmarking study of a selection of wave energy converters. Renewable Energy, 41, 44-63. Retrieved from http://linkinghub.elsevier.com/retrieve/pii/S0960148111005672 doi:

Badcock-Broe, A., Flynn, R., George, S., Gruet, R., \& Medic, N. (2014). Wave and Tidal Energy Market Deployment Strategy for Europe (Tech. Rep. No. June). Retrieved from http://www.si-ocean.eu/en/Market-Deployment/Market-Deployment-Strategy/

Bloomberg. (n.d.). Bloomberg-Energy. Retrieved from http://www.bloomberg.com/energy

Boehlert, G. W., \& Gill, A. B. (2010, June). Environmental and ecological effects of ocean renewable energy development: A current synthesis. Oceanography, 23. doi:

Bozzi, S., Archetti, R., \& Passoni, G. (2014). Wave electricity production in Italian offshore: A preliminary investigation. Renewable Energy, 62, 407-416. Retrieved from http://dx.doi.org/10.1016/j.renene.2013.07.030 doi:

Bozzi, S., Milano, P., \& Passoni, G. (2011). Mediterranean sea: comparison among different technologies. In Asme 2011 30th international conference on ocean, offshore and arctic engineering volume 5: Ocean space utilization; ocean renewable energy rotterdam, the netherlands, june 1924, 2011 (pp. 1-6). doi:

Bozzi, S., Miquel, A. M., Antonini, A., Passoni, G., \& Archetti, R. (2013). Modeling of a point absorber for energy conversion in Italian seas. Energies, 6(6), 3033-3051. doi:

Brendan, C. (2015). Personal Communication. Sustainable Energy Authority of Ireland (SEAI). 
Commission, E. (2017). NER300 Documentation, Accessed on 20-01-201\%. Retrieved from http://europa.eu/clima/policies/lowcarbon/ner300_en

Contestabile, P., Di Lauro, E., Buccino, M., \& Vicinanza, D. (2017). Economic assessment of overtopping breakwater for energy conversion (obrec): A case study in western australia. Sustainability, $9(1)$.

Cradden, L., Mouslim, H., Duperray, O., \& Ingram, D. (2012). Joint Exploitation of Wave and Offshore Wind Power. Energy.

Dalton, G., Allan, G., Beaumont, N., Georgakaki, A., Hacking, N., Hooper, T., ... Stallard, T. (2015). Economic and socio-economic assessment methods for ocean renewable energy: Public and private perspectives. Renewable and Sustainable Energy Reviews, 45, 850-878. Retrieved from http://linkinghub.elsevier.com/retrieve/pii/S1364032115000787 doi:

Day, A., Babarit, A., Fontaine, A., He, Y.-P., Kraskowski, M., Murai, M., ... Shin, H.-K. (2015). Hydrodynamic modelling of marine renewable energy devices: A state of the art review. Ocean Engineering, 108, 46-69. Retrieved from http://linkinghub.elsevier.com/retrieve/pii/S0029801815002280 doi:

De Decker, J., \& Woyte, A. (2013, jan). Review of the various proposals for the European offshore grid. Renew. Energy, 49, 58-62. doi:

EPA. (n.d.). Clean Energy- Air Emissions, Accessed on March 2016. Retrieved from http://www.epa.gov/cleanenergy/energy-and-you/affect/air-emissions.html

European Commission. (2009). Directive 2009/29/EC. European Commission. Retrieved from http://eur-lex.europa.eu/LexUriServ/LexUriServ.do?uri=0J :L:2009:140:0063: 0087:EN : PDF

European Commission. (2014). Study of the Benefits of a Meshed Offshore Grid in Northern Seas Region (Tech. Rep.).

European Commission. (2017). NER 300 programme Policy, Accessed on 10-02-2017. Retrieved from http://europa.eu/clima/policies/lowcarbon/ner300_en

Falcão, A. F. D. O. (2010, apr). Wave energy utilization: A review of the technologies. Renewable and Sustainable Energy Reviews, 14(3), 899-918. Retrieved from http://linkinghub.elsevier.com/retrieve/pii/S1364032109002652 doi:

France, D. (2007). Arrete $d u$ 1Mars 2007 (Tech. Rep.). JORF n95 du 22 avril 2007 page 7146 . Retrieved from http://legifrance.gouv.fr/eli/arrete/2007/3/1/INDI0709633A/jo/texte

Fraunhofer, \& ECORYS. (2017). Study on Lessons for Ocean Energy Development (Tech. Rep.). European Commission. Retrieved from https://publications. europa.eu/en/publication-detail/-/publication/03c9b48d-66af-11e7-b2f2 doi:

Friedrich, D., \& Lavidas, G. (2015). Combining offshore and onshore renewables with energy storage and diesel generators in a stand-alone Hybrid Energy System. In Oses offshore energy 83 storage symposium, july 1-3. Edinburgh. Retrieved from http://www.see.ed.ac.uk/drupal/oses/

GSE. (2015). Gestore Servizi Energetici. Retrieved from http://www.gse.it/en/qualificationandcertificates/Theall-inclusivefeed-intariff/Pages/defa

Gunn, K., \& Stock-Williams, C. (2012). Quantifying the global wave power resource. Renewable Energy, 44, 296-304. Retrieved from http://dx.doi.org/10.1016/j.renene.2012.01.101 doi:

Hedegaard, K., \& Meibom, P. (2012, jan). Wind power impacts and electricity storage-A time scale perspective. Renew. Energy, 37(1), 318-324. doi:

Hervás Soriano, F., \& Mulatero, F. (2011, jun). EU Research and Innovation (R\&I) in renewable energies: The role of the Strategic Energy Technology Plan (SET-Plan). Energy Policy, 39(6), 3582-3590. Retrieved from http://linkinghub.elsevier.com/retrieve/pii/S0301421511002485 doi:

Ibarra-Berastegi, G., Sáenz, J., Ulazia, A., Serras, P., Esnaola, G., \& Garcia-Soto, C. (2018). 
Electricity production, capacity factor, and plant efficiency index at the Mutriku wave farm (20142016). Ocean Engineering, 147(September 2017), 20-29. doi:

IEA. (n.d.). International Energy Agency, Accessed on 21-12-2016. Retrieved from http://www.iea.org/

Ingram, D., Smith, G., Bittencourt-Ferreira, C., \& Smith, H. (2011). EquiMar: Protocols for the Equitable Assessment of Marine Energy Converters (No. 213380). doi:

Jacobson, M. Z., \& Delucchi, M. a. (2011). Providing all global energy with wind, water, and solar power, Part I: Technologies, energy resources, quantities and areas of infrastructure, and materials. Energy Policy, 39(3), 1154-1169. Retrieved from http://dx.doi.org/10.1016/j.enpol.2010.11.040 doi:

Jacobson, M. Z., Delucchi, M. A., Bauer, Z. A., Goodman, S. C., Chapman, W. E., Cameron, M. A., ... Yachanin, A. S. (2017). 100\% Clean and Renewable Wind, Water, and Sunlight All-Sector Energy Roadmaps for 139 Countries of the World. Joule, 1-14. Retrieved from http://linkinghub.elsevier.com/retrieve/pii/S2542435117300120 doi:

Kapetaki, Z., \& Scowcroft, J. (2017). Overview of carbon capture and storage (ccs) demonstration project business models: Risks and enablers on the two sides of the atlantic. Energy Procedia, 114, 6623 - 6630. Retrieved from http://www.sciencedirect.com/science/article/pii/S1876610217320180 (13th International Conference on Greenhouse Gas Control Technologies, GHGT-13, 14-18 November 2016, Lausanne, Switzerland) doi:

Krozer, Y. (2013, feb). Cost and benefit of renewable energy in the European Union. Renew. Energy, 50, 68-73. doi:

Lavidas, G. (2016). Wave Energy Resource Modelling and Energy Pattern Identification Using a Spectral Wave Model (Doctor of ed.) [Doctor of Philosophy (Ph.D)]. Edinburgh. Retrieved from https://www.era.lib.ed.ac.uk/handle/1842/25506

Lavidas, G., \& Agarwal, A. (2017). Combining Offshore Renewable Energies and Addressing Variability. In Energy in transportation (eint), ashrae. Athens: ASHRAE. Retrieved from http: //www.ashrae.gr/eint2017.php

Lavidas, G., \& Venugopal, V. (2017a). A 35 year high-resolution wave atlas for nearshore energy production and economics at the Aegean Sea. Renewable Energy, 103, 401-417. Retrieved from http://linkinghub.elsevier.com/retrieve/pii/S0960148116310394 doi:

Lavidas, G., \& Venugopal, V. (2017b). Characterising the wave power potential of the Scottish coastal environment. International Journal of Sustainable Energy, $00(0)$, 1-20. Retrieved from https://www.tandfonline.com/doi/full/10.1080/14786451.2017.1347172 doi:

Lavidas, G., \& Venugopal, V. (2017c). Characterising the wave power potential of the Scottish coastal environment. International Journal of Sustainable Energy. doi:

Lavidas, G., \& Venugopal, V. (2018). Application of Numerical Wave Models at European Coastlines: A Review, Under Press. Renewable \& Sustainable Energy Reviews.

Lavidas, G., Venugopal, V., \& Agarwal, A. (2016). Long-term evaluation of the wave climate and energy potential in the Mediterranean Sea. In Sustainable hydraulics in the era of global change - proceedings of the 4 th european congress of the international association of hydroenvironment engineering and research, iahr 2016.

Lavidas, G., Venugopal, V., \& Friedrich, D. (2017). Wave energy extraction in Scotland through an improved nearshore wave atlas. International Journal of Marine Energy, 17, 64-83. Retrieved from http://dx.doi.org/10.1016/j.ijome.2017.01.008 doi:

Leeney, R. H., Greaves, D., Conley, D., \& O'Hagan, A. M. (2014). Environmental impact assessments for wave energy developments learning from existing activities and informing future research priorities. Ocean \& Coastal Management, 99, 14 - 22. (Science in support of governance of wave and tidal energy developments) doi:

Luppa, C., Cavallaro, L., Foti, E., \& Vicinanza, D. (2015). Potential wave energy production by different wave energy converters around Sicily. Journal of Renewable and Sustainable Energy, 7(6), 061701. Retrieved from 
http://scitation.aip.org/content/aip/journal/jrse/7/6/10.1063/1.4936397

doi:

Magagna, D., Monfardini, R., \& Uihlein, A. (2016). JRC Ocean Energy Status Report (Tech. Rep.). Retrieved from http://publications.europa.eu/en/publication-detail/-/publication/e22b8458-f412-11e6-8a35doi:

Magagna, D., \& Uihlein, A. (2015). Ocean energy development in Europe: Current status and future perspectives. International Journal of Marine Energy, 11, 84-104. doi:

Magagna, D., Uihlein, A., Silva, M., \& Raventos, A. (2015). Wave and tidal energy in Europe : assessing present technologies. In Proceedings of the 11th european wave and tidal energy conference 6-11th sept 2015, nantes, france (pp. 1-6).

Makris, C., Galiatsatou, P., Tolika, K., Anagnostopoulou, C., Kombiadou, K., Prinos, P., ... Rusu, E. (2016, Dec 01). Climate change effects on the marine characteristics of the aegean and ionian seas. Ocean Dynamics, 66(12), 1603-1635. Retrieved from https://doi.org/10.1007/s10236-016-1008-1 doi:

Margheritini, L., Hansen, A. M., \& Frigaard, P. (2012). A method for eia scoping of wave energy convertersbased on classification of the used technology. Environmental Impact Assessment Review, 32(1), 33 - 44. doi:

NER400. (n.d.).

Ocean, S. (2013). Ocean Energy: Cost of Energy and Cost Reduction Opportunities (Tech. Rep. No. May). Retrieved from http://si-ocean.eu/en/upload/docs/WP3/CoE report 3_2 final.pdf

Ocean Energy Forum. (2016). Ocean Energy Strategic Roadmap 2016, building ocean energy for Europe (Tech. Rep.). Retrieved from https://webgate.ec.europa.eu/maritimeforum/en/frontpage/1036

O'Connor, M., Lewis, T., \& Dalton, G. (2013). Weather window analysis of Irish west coast wave data with relevance to operations \& maintenance of marine renewables. Renewable Energy, 52, 57-66. Retrieved from http://dx.doi.org/10.1016/j.renene.2012.10.021 doi:

OES. (2015). International Levelised Cost Of Energy for Ocean Energy Technologies (Tech. Rep. No. May).

Parliament, E. (2009). The European Parliament. Directive of the European Parliament and of the Council on the promotion of the use of energy from renewable sources amending and subsequently repealing directives 2001/77/ec and 2003/30/ec. (Tech. Rep.).

Pecher, A., Kofoed, J. P., Le Crom, I., Neumann, F., \& Azevedo, E. D. B. (2011). Performance assessment of the pico owc power plant following the equimar methodology. In Proceedings of the 21st international offshore and polar engineering conference. international society of offshore and polar engineers. doi:

Rahm, M. (2010). Ocean Wave Energy, Underwater Substation System for Wave Energy Converters (Ph.D Thesis). Uppsala Universitet.

Reikard, G., Robertson, B., \& Bidlot, J.-R. (2015). Combining wave energy with wind and solar: Short-term forecasting. Renew. Energy, 81, 442-456. doi:

Rusu, E., \& Onea, F. (2016). Estimation of the wave energy conversion efficiency in the Atlantic Ocean close to the European islands. Renewable Energy, 85, 687-703. Retrieved from http://dx.doi.org/10.1016/j.renene.2015.07.042 doi:

Rusu, E., \& Onea, F. (2018). A review of the technologies for wave energy extraction. Clean Energy(March), 1-10. Retrieved from https://academic.oup.com/ce/advance-article/doi/10.1093/ce/zky003/4924611 doi:

Rusu, L., \& Onea, F. (2015). Assessment of the performances of various wave energy converters along the European continental coasts. Energy, 82, 889-904. Retrieved from http://linkinghub.elsevier.com/retrieve/pii/S0360544215001231 doi:

Rusu, L., \& Onea, F. (2016). The performance of some state-of-the-art wave energy converters in locations with the worldwide highest wave power. Re- 
newable and Sustainable Energy Reviews(August 2015), 0-1. Retrieved from http://dx.doi.org/10.1016/j.rser.2016.11.123 doi:

Sasaki, W. (2017). Predictability of global offshore wind and wave power. International Journal of Marine Energy, 17, 98-109. Retrieved from http://dx.doi.org/10.1016/j.ijome.2017.01.003 doi:

Schaber, K., Steinke, F., \& Hamacher, T. (2012, apr). Transmission grid extensions for the integration of variable renewable energies in Europe: Who benefits where? Energy Policy, 43, 123-135. doi:

Spain. (n.d.). (Tech. Rep.).

Sterl, A., \& Caires, S. (2005). Climatology, variability and extrema of ocean waves: The webbased KNMI/ERA-40 wave atlas. International Journal of Climatology, 25(7), 963-977. doi:

Stoutenburg, E. D., Jenkins, N., \& Jacobson, M. Z. (2010, dec). Power output variations of co-located offshore wind turbines and wave energy converters in California. Renewable Energy, 35(12), 2781-2791. Retrieved from http://linkinghub.elsevier.com/retrieve/pii/S0960148110002004 doi:

Takahashi, S., Nakada, H., Ohneda, H., \& Shikamori, M. (1992). Wave power conversion by a prototype wave power extracting caisson in Sakata port. In Proceedings of the 23rd international conference on coastal engineering, venice, italy, 49 october 1992.

Torre-Enciso, Y., Ortubia, I., de Aguileta, L. L., \& Marques, J. (2009). Mutriku wave power plant: from the thinking out to the reality. In Proceedings of the 8th european wave and tidal energy conference, uppsala, sweden. doi:

Venugopal, V. (2016). Lecture notes "marine energy wave analysis 3", university of edinburgh.

Verbruggen, A., Fischedick, M., Moomaw, W., Weir, T., Nadaï, A., Nilsson, L. J., ... Sathaye, J. (2010, feb). Renewable energy costs, potentials, barriers: Conceptual issues. Energy Policy, 38(2), 850-861. doi:

Vicinanza, D., Cappietti, L., \& Contestabile, P. (2007). Assessment of Wave Energy around Italy. In 8th european wave and tidal energy (pp. 256-262). Uppsala, Sweden.

Vicinanza, D., Contestabile, P., \& Ferrante, V. (2013). Wave energy potential in the north-west of Sardinia (Italy). Renewable Energy, 50, 506-521. Retrieved from http://dx.doi.org/10.1016/j.renene.2012.07.015 doi:

Vicinanza, D., Ferrante, V., Zambianchi, E., Pratico, C., Riefolo, L., Abadal, J., .. Maljkovic, D. (2015). BLUENE - BLUe ENErgy for Mediterranean Sea. In Proceedings of the 11th european wave and tidal energy conference 6-11th sept 2015, nantes, france (pp. 1-8).

Vinoth, J., \& Young, I. R. (2011, mar). Global Estimates of Extreme Wind Speed and Wave Height. Journal of Climate, 24(6), 1647-1665. Retrieved from http://journals.ametsoc.org/doi/abs/10.1175/2010JCLI3680.1 doi:

Zacharioudaki, A., Korres, G., \& Perivoliotis, L. (2015). Wave climate of the Hellenic Seas obtained from a wave hindcast for the period 19602001. Ocean Dynamics, 65 (6), 795816. Retrieved from http://link.springer.com/10.1007/s10236-015-0840-z doi: 


\section{Tables}

Table 1.: Information about the status of the selected Ocean technologies

\begin{tabular}{cccccc}
\hline Project Name & $1^{\text {st }}$ call & $2^{\text {nd }}$ call & Euro awarded & Country/Region & Type \\
\hline WestWave & & $\mathrm{X}$ & $23,286,333 €$ & Ireland & Wave \\
Sound of Islay & $\mathrm{X}$ & & $20,650,000 €$ & United Kingdom & Tidal \\
Kyle Rhea & $\mathrm{X}$ & & $16,777,548 €$ & United Kingdom & Tidal \\
SWELL & & $\mathrm{X}$ & $9,139,937 €$ & Portugal & Wave \\
NEMO & & $\mathrm{X}$ & $72,131,333 €$ & Martinique/France & Ocean Thermal \\
\hline
\end{tabular}

Table 2.: Indicative Expected production of Projects in MWh

\begin{tabular}{cccccc}
\hline Project & Installed Capacity $(\mathrm{MW})$ & Funds NER300 & Low $(20 \%)$ per year & High(40\%) per year & Years of Operation \\
\hline West Wave & 5 & $23,286,333 €$ & 8,760 & 17,520 & 20 \\
SWELL & 5.6 & $9,139,937 €$ & 9,811 & 19,622 & 20 \\
\hline
\end{tabular}

Table 3.: Indicative parameters of the expected production of the projects in MWh

\begin{tabular}{cc}
\hline Installed Capacity & $5 \mathrm{MW}$ \\
Capacity factor & $10-30 \%$ (increments of $2.5 \%$ ) \\
Cost $(€ / \mathrm{MW})$ & $1.5-3 \mathrm{~m} €$ (increments of $250 \mathrm{k} €$ ) \\
Toe & $11630 \mathrm{kWh}$ \\
$\mathrm{bbl}$ & (Barrel of oil equivalent) $150 \mathrm{~kg}$ \\
$€ / \mathrm{bbl}$ & 55 \\
\hline
\end{tabular}




\section{Figures}



Figure 1.: Annual mean wave power as estimated by a long-term hindcast by Gunn and Stock-Williams (2012)


Figure 2.: Some of the basic principles for ocean wave extraction (Rahm, 2010; Venugopal, 2016) 


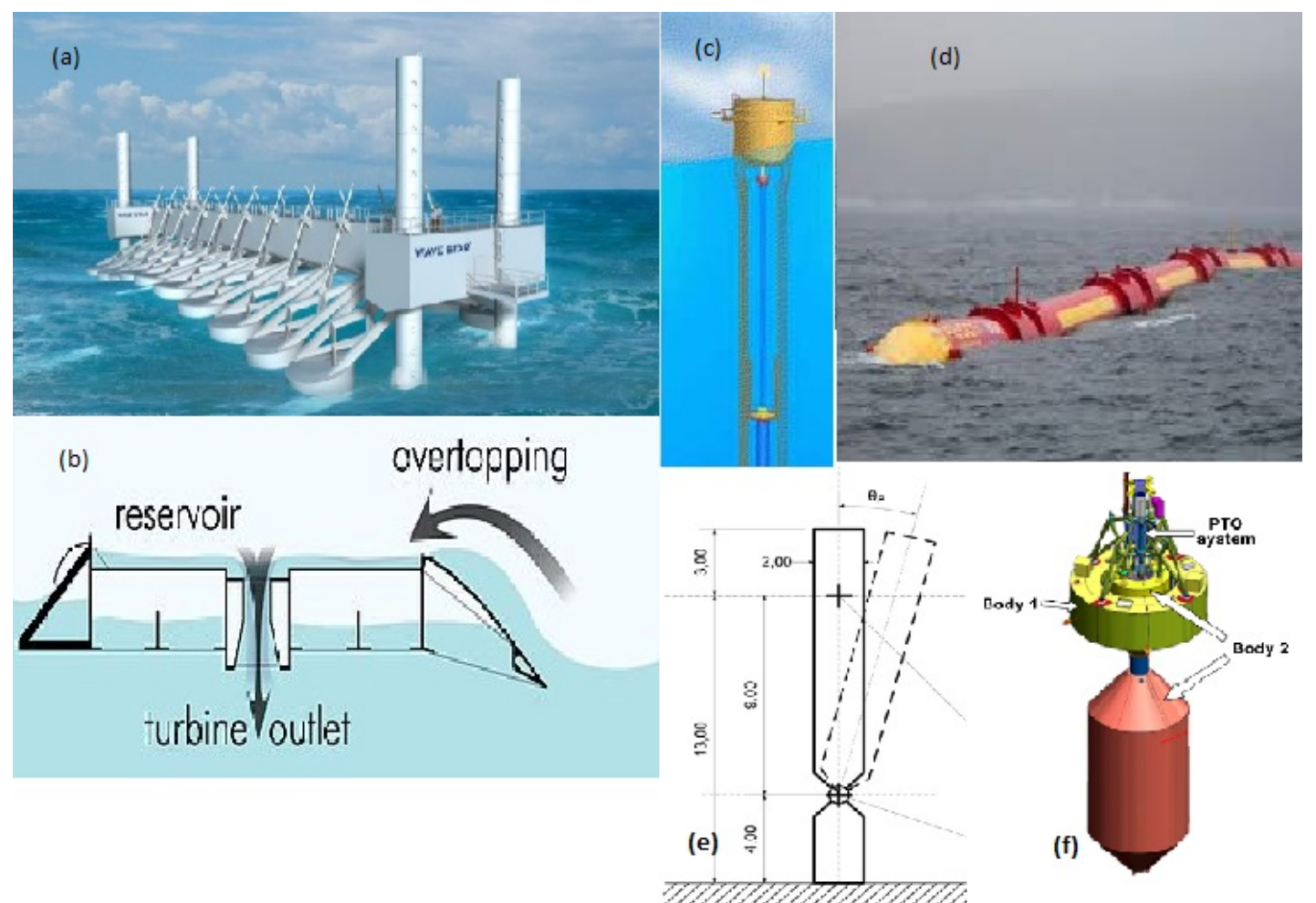

Figure 3.: Representative devices for potential production by wave energy (a) WaveStar (b) WaveDragon (c) AquaBuoy (d) Pelamis, (e) Bottom fixed flap Oyster resemblance (f) WaveBob

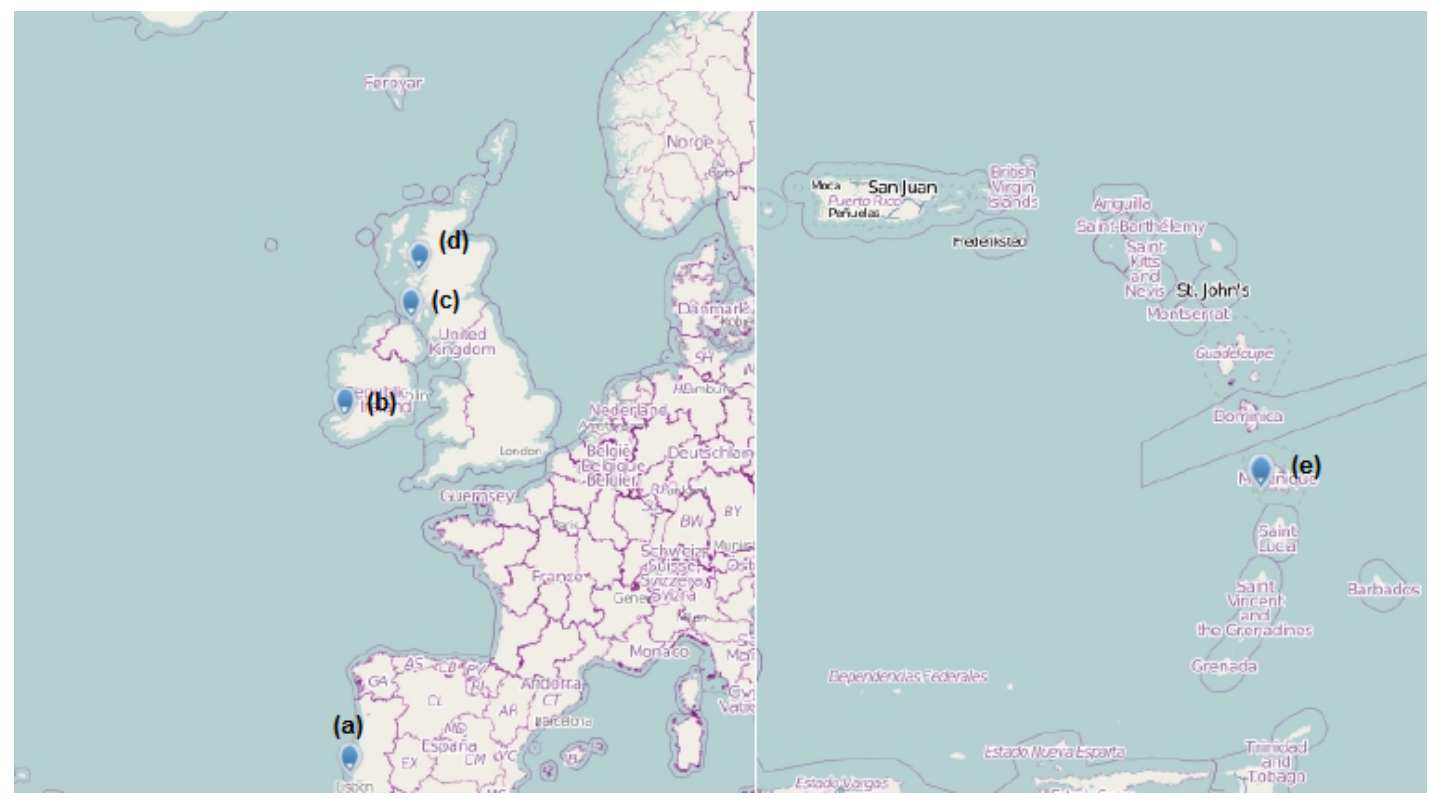

Figure 4.: Spatial information concerning the technologies and the accepted calls for ocean energy by the NER300, (a): SWELL, (b): WestWave, (c): Sound of Islay, (d): Kyle Rhea, (e): NEMO 


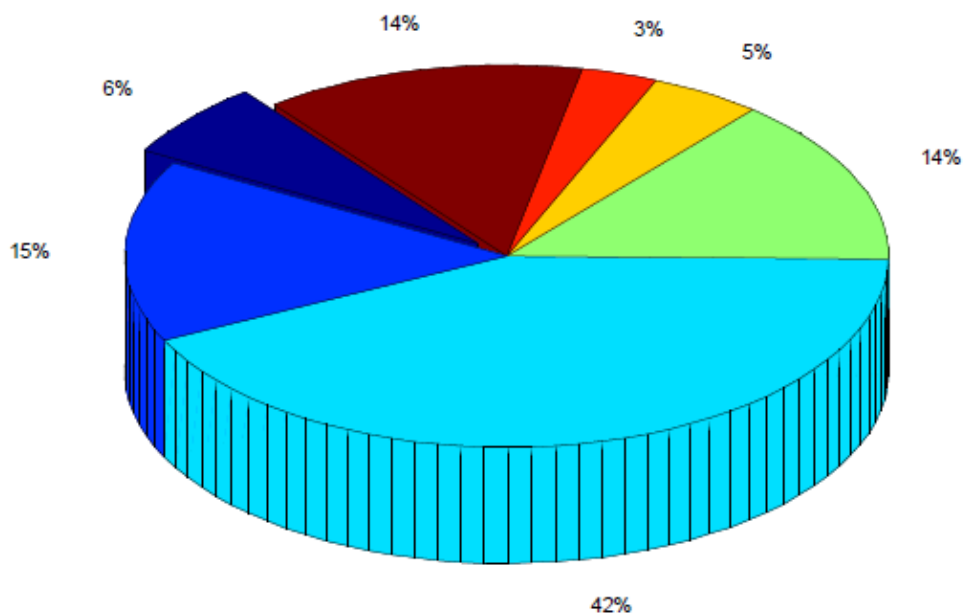

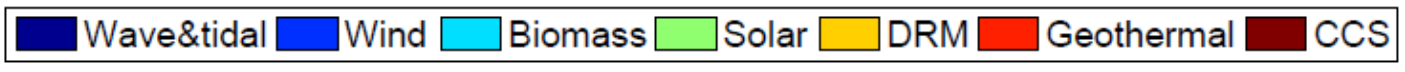

Figure 5.: NER300 (1st and 2nd call) allocated funds per technology
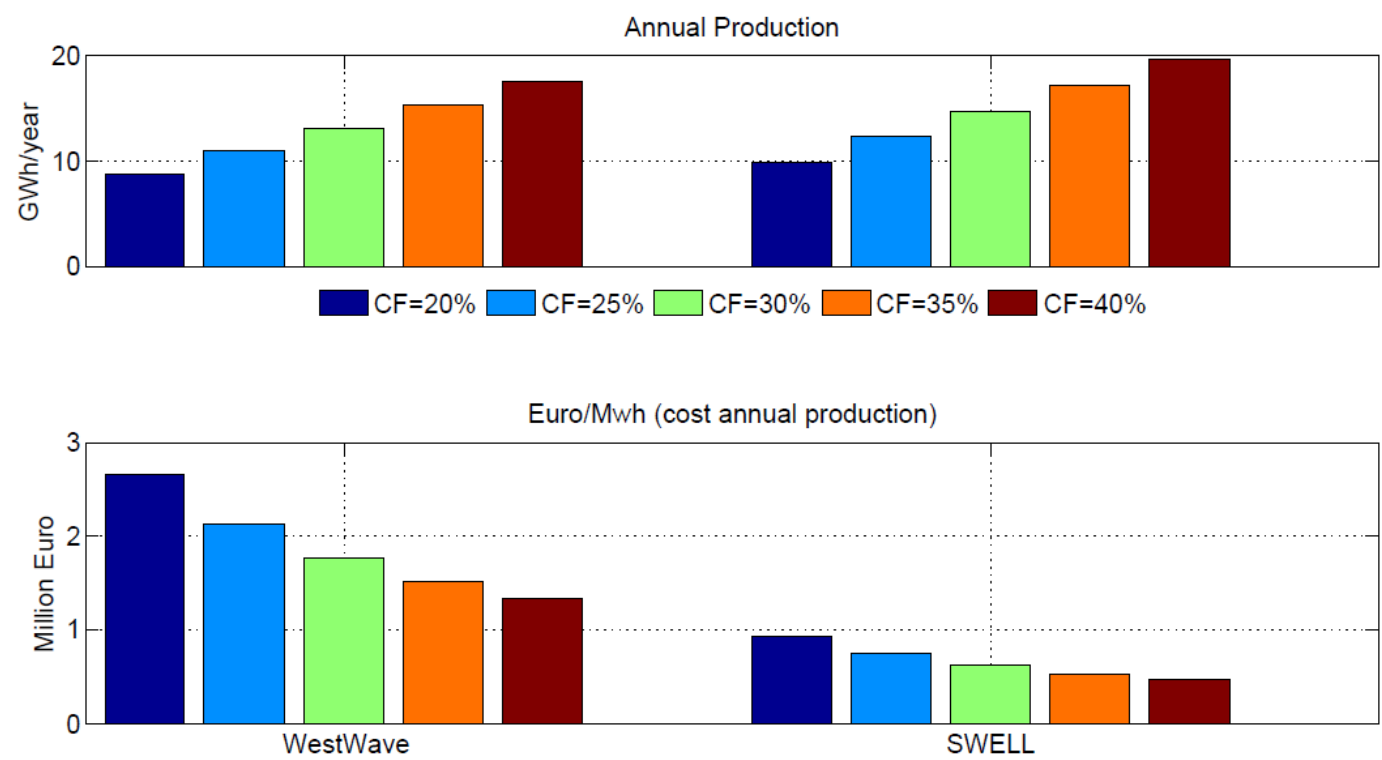

Figure 6.: Production scenarios of the two projects and the corresponding cost per MWh in correlation to public funds 

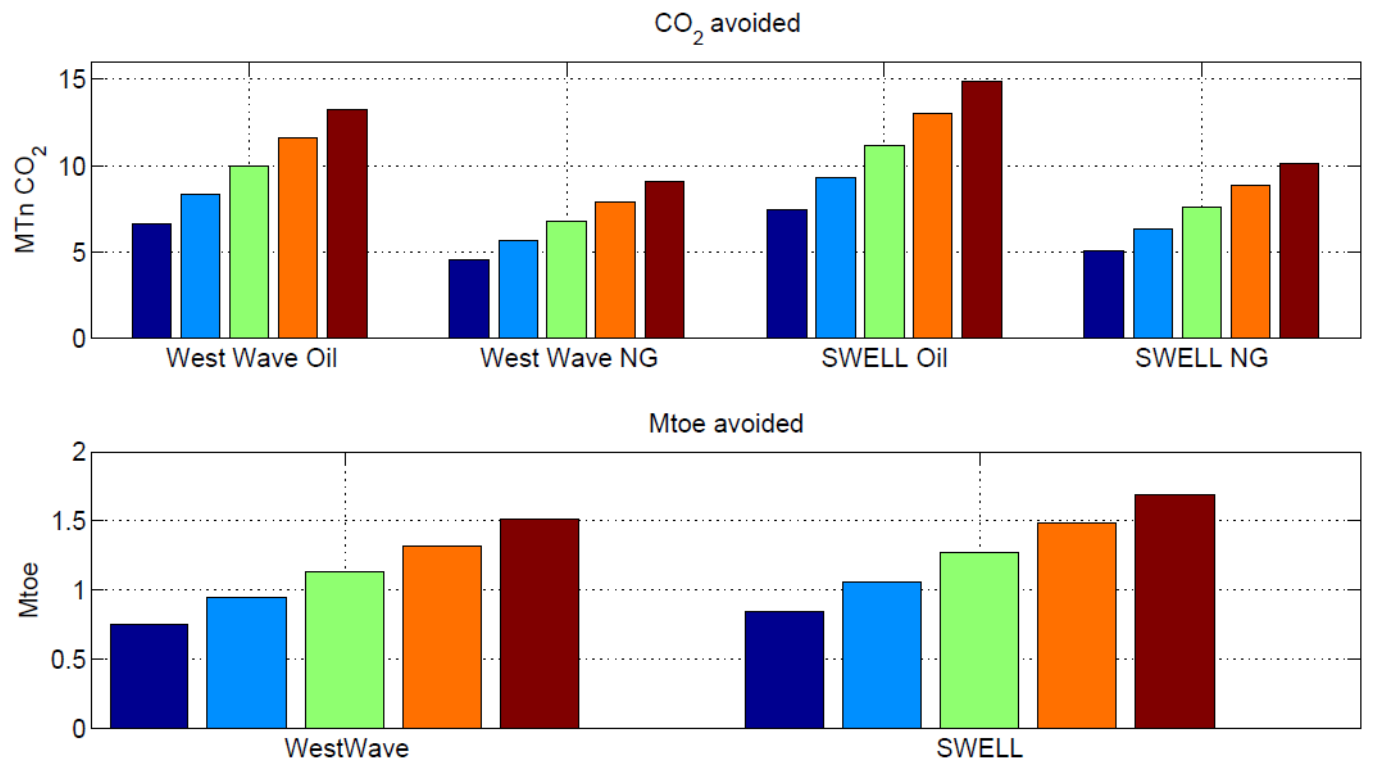

Figure 7.: Avoided emissions of $\mathrm{CO}_{2}$ and avoided imports of energy based on the scenarios of production for the projects, the colour coding follows the increments of $\mathrm{CF}$ as indicated above

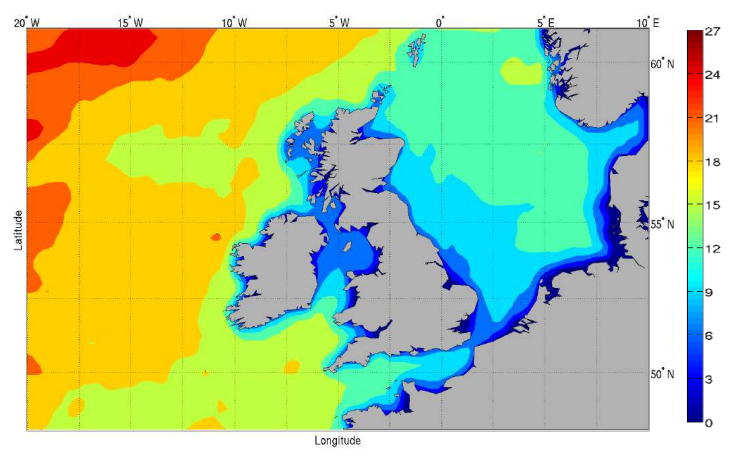

United Kingdom

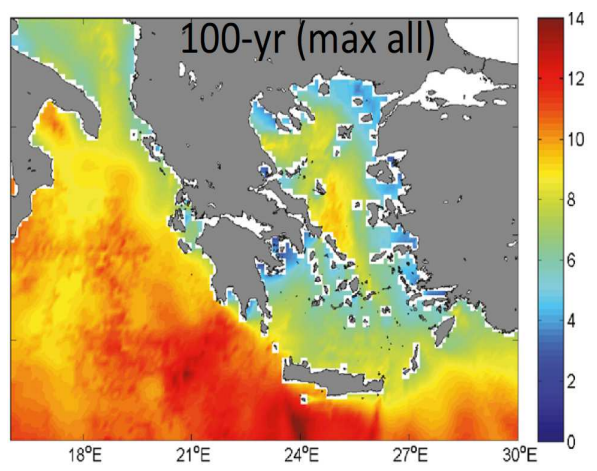

Greece

Figure 8.: Indicative 100 year return period of wave heights top panel the UK, North Sea, Ireland obtained from (Agarwal, 2015), and representative return values for the Greek region obtained from (Zacharioudaki et al., 2015). 

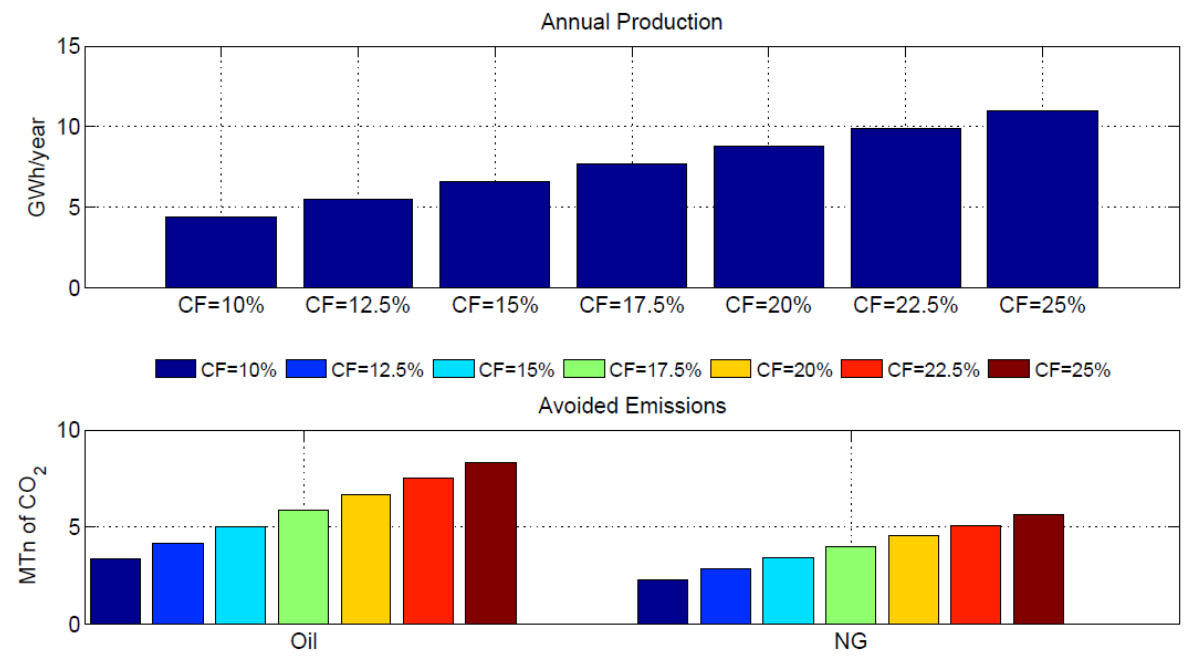

Figure 9.: Expected production and avoided emission by the WEC farm

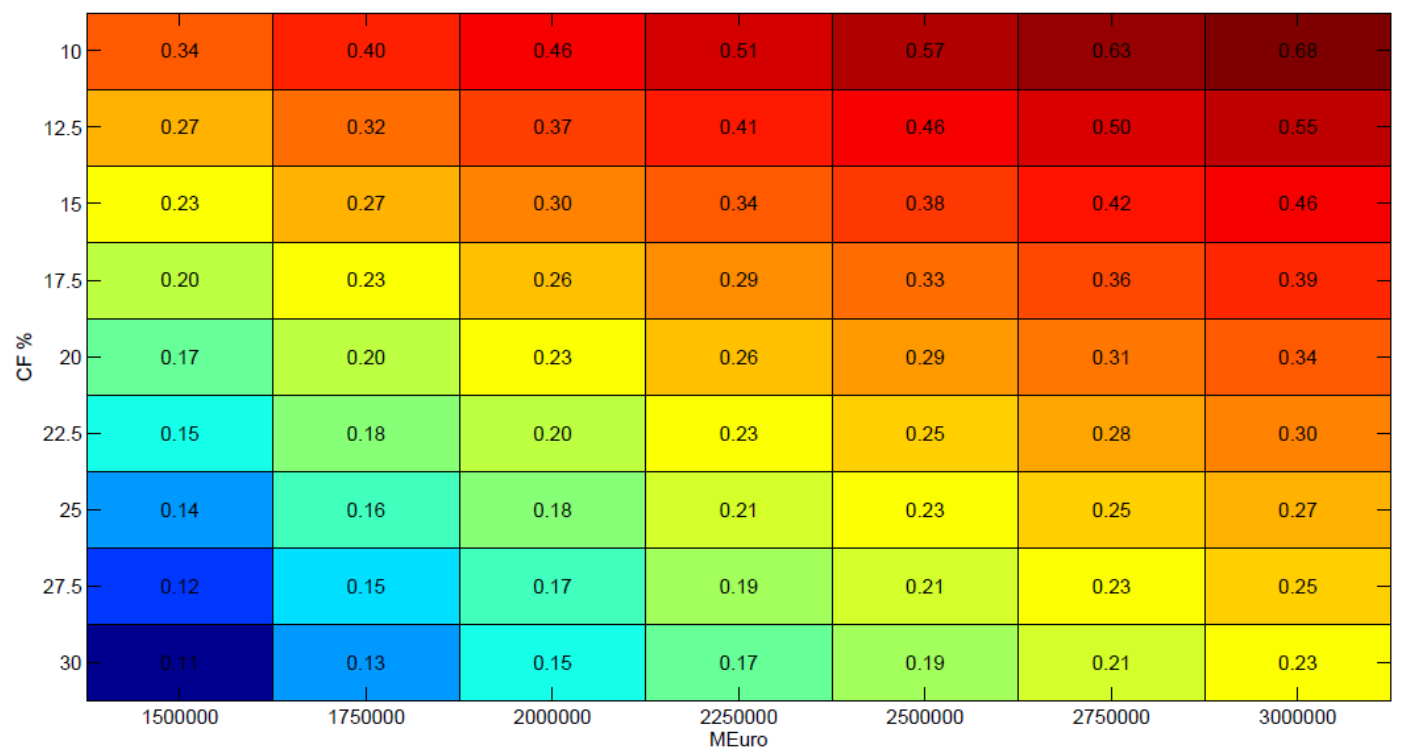

Figure 10.: Sensitivity analysis concerning the cost of energy (COE) in Euro per $\mathrm{kWh}$ produced, the x-axis has the CAPEX and the y-axis the CF. Each COE value is the results of the different costs and energy production. 

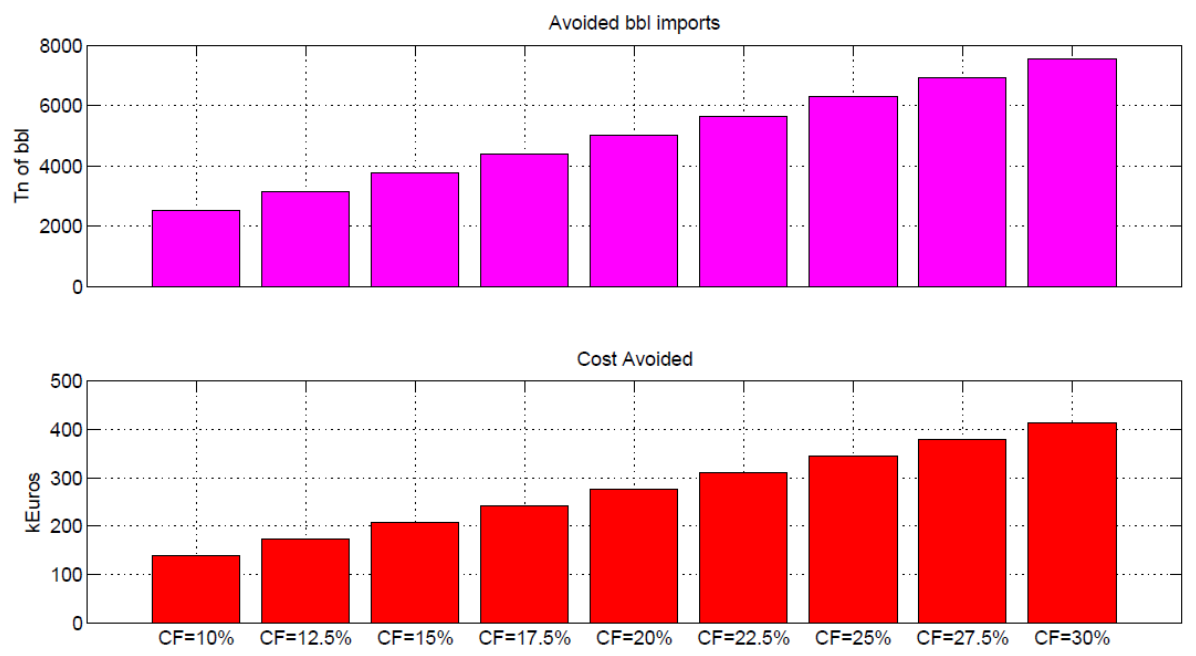

Figure 11.: Avoided imports of energy products benefits in bbl and capital 